\title{
Pulmonary expression of Pla2g5 during lung damage in mice induced by fipronil and lipopolysaccharide interaction
}

\begin{abstract}
Arif Ahmad Pandit *
Department of Animal Biotechnology, School of Animal Biotechnology, Guru Angad Dev Veterinary and Animals Sciences University, Ludhiana-141004 (Punjab), India

R.S. Sethi

Department of Animal Biotechnology, School of Animal Biotechnology, Guru Angad Dev Veterinary and Animals Sciences University, Ludhiana-141004 (Punjab), India

${ }^{*}$ Corresponding author. E-mail: arif.pandit@gmail.com

Abstract

With Indian pesticide industry touching new heights each year in terms of production and sale, its ill effects on health cannot just be ignored. Humans, as well as animals, are under the constant threat of being exposed to environmental pollutants like endotoxins and pesticides which are present ubiquitously in our surroundings. Phenylpyrazoles like fipronil were introduced into the Indian market with an aim to oversee the menace of insecticide resistance and public health hazards experienced with more commonly used pesticide but its adverse effects on the pulmonary system are now being reported globally. We reported first data that the Planar cell Polarity (PCP) pathway was the top dysregulated pathway during fipronil induced lung damage. In order to further elucidate the underlying molecular mechanisms, we analysed the data generated by gene expression profiling in lung tissues using biocomputational approaches. We found Eicosanoid signalling as one of the top enriched pathways dysregulated during fipronil and or endotoxininduced lung inflammation. Global view of genes showed Pla2g5 as top differentially expressed gene with 1.6, 3.9, 1.2, 3.1 and 4.3-folds expression in lipopolysaccharide (LPS), high dose of fipronil $(9.5 \mathrm{mg} / \mathrm{kg})$ alone or in combination with LPS and low dose of fipronil $(4.75 \mathrm{mg} / \mathrm{kg})$ alone or in combination with LPS, respectively which was validated using qPCR and immunohistochemistry. The data suggest a role Pla2g5 to activate eicosanoid signalling in fipronil and or LPS induced lung inflammation in mice.
\end{abstract}

Keywords: Eicosanoid, Fipronil, Immunohistochemistry, LPS, Pla2g5, qPCR

\section{Article Info}

DOI: 10.31018/jans.v11i2.2043

Received: March 19, 2019

Revised: April 8, 2019

Accepted: April 17, 2019

\section{How to Cite}

Pandit, A. A. and Sethi, R.S. (2019). Pulmonary expression of Pla2g5 during lung damage in mice induced by fipronil and lipopolysaccharide interaction. Journal of $A p$ plied and Natural Science, 11(2): 285- 290 https:// doi.org/10.31018/

jans.v11i2.2043

\section{INTRODUCTION}

Average crop yields have increased past several years which is partly attributed to the use of pesticides in controlling diseases affecting crops (Hossard et al., 2014). The Indian pesticide industry has not been very far from the rest of the world in terms of production and usage of pesticides. India lacks behind Japan, China and Latin american countries in terms of pesticide consumption (Subash et al., 2017) India was the leading country in using dichloro diphenyl trichloroethane (DDT) until its ban for agricultural use in 1989. It was the only country apart from the US, which had used more than 100,000 tonnes of DDT in agricultural and malaria control programs (Kannan et al., 1995). Later on, organochlorines topped the list (up to $40 \%$ ) of all the pesticides used (Gupta 2004). Besides this, there are many other pesticides which belong to the different classes and are highly hazardous (Abhilash, et al., 2009).
Phenylpyrazoles are relatively new class insecticides which were introduced to oversee the menace of insecticide resistance and public health hazards experienced with more commonly used pesticide families like pyrethroid, organophosphate, and carbamates (Kidd et al., 1991). Fipronil chemically is a pyrazole- 3-carbonitrile and acts at the Gamma-Aminobutyric acid (GABA) receptor as a non-competitive blocker of the GABA-gated chloride channels of neurons in the central nervous system. Binding to mammalian GABA-A and GABA-C receptors also poses its risk to human health (Hainzl et al., 1996). Contamination of food crops by pesticides is very likely to happen if applied to plants and fruits close to harvest. Animals after consuming such contaminated feedstuff likely to accumulate these hazardous chemicals in meat and milk byproducts. Fipronil residues have been detected in drinking water and in different food products which are used by humans such as maize, Chinese cabbage and milk (Liu et al., 
2008).

Besides pesticide contacts, agricultural worker (mainly livestock), waste treatment, textile industries (primarily cotton), and to a lesser degree in cigarette factories, paper mills and dental offices are always prone to exposure to endotoxin which has been related to intense respiratory side effects and decrements in the lung function (Duquenne et al., 2013). It has earlier been reported that pesticide exposure along with endotoxins act synergistically to damage the lung (Verma et al., 2018, Tewari et al., 2017, Sethi et al., 2017, Pandit et al., 2017, Verma et al., 2016, Sandeep et al., 2016 and Pandit et al., 2016). Similarly, we reported fipronil to cause lung inflammation in both in-vivo and in-vitro models (Merkowsky et al., 2016, Sandeep et al., 2016, Arif Ahmad Pandit 2018). Recently we demonstrated that fipronil and or endotoxin-induced lung damage was by activation of the PCP pathway in a dose-dependent manner (Pandit et al., 2019). Based on our transcriptome analysis we found eicosanoid signalling as one of the enriched signalling pathway dysregulated during fipronil and or endotoxin-induced lung inflammation.

Further, Pla2g5 is a member of the secretory phospholipase A2 family which is located in a close association with a cluster of secretory PLA2 genes on chromosome 1 in both humans and mouse (Tischfield et al., 1996). Its primary function is to catalyse the hydrolysis of membrane phospholipids to generate lysophospholipids and free fatty acids including arachidonic acid and trigger eicosanoid signalling (Burke et al., 2009). Group V PLA2 (Pla2g5) is prevalently expressed by innate immune cells, including dendritic cells and macrophages (Giannattasio et al., 2010), as well as epithelial cells (Ohta et al., 2013) and releases lysophosphatidylcholine (LPC) and the FFAs linoleic acid (LA) and oleic acid (OA) which aid in inflammation process.

However, there is no report on the expression of Pla2g5 in lungs following exposure to fipronil alone or in combination with endotoxins. So we tested the hypothesis that fipronil or/and endotoxin alter the pulmonary expression of Pla2g5 in a Swiss albino mice model. We present the first data on the Pla2g5 expression in the lungs in mice following exposure to fipronil and or endotoxins.

\section{MATERIALS AND METHODS}

In the present investigation, the effect of oral administration of fipronil and or endotoxin/LPS was undertaken in mice model to explore the expression of Pla2g5 concerning eicosanoid signalling to evaluate the differences among two dose groups. Chemicals: Technical grade Fipronil PESTANAL $®$ (Catalogue no. 46451) purity $98.6 \%$ and Corn oil (Catalogue no. C8267) were procured from Sigma Aldrich, Bangalore, India.

Experimental animals: The experimental protocols and use of animals was dually approved by Guru Angad Dev Veterinary and Animal Sciences University (GADVASU), Ludhiana dually as per the guidelines from Committee for Control and Supervision of Experiments on Animals (CPCSEA) with reference no: GADVASU/2015/ IAEC/29/011. We purchased forty-two healthy male Swiss albino mice from Lala Lajpat Rai University of Veterinary and Animal Sciences, Hisar Haryana. The mice were between 6-8 weeks of age. We kept the mice under standard conditions of $12 \mathrm{hr}$. light and $12 \mathrm{hr}$. in polypropylene cages. dark cycle at small animal housing hall, GADVASU, Ludhiana. Before using the animals for experiment were acclimatized for one week by feeding them synthetic pelleted diet and water ad libitum.

Doses and exposure schedule: The experimental protocols have been described previously (Pandit et al., 2019). Briefly, animals were randomly divided into three groups viz. two treatments and one control ( $n=14$ in each group). Lethal dose $\left(L D_{50}\right)$ of fipronil in male mice is $95 \mathrm{mg} /$ $\mathrm{Kg}$ (Tomlin 2009). We chose to give two different doses of fipronil based on its $L_{50}$ concentration, one treatment group was given high dose $1 / 10^{\text {th }}$ of $\mathrm{LD}_{50}(9.5 \mathrm{mg} / \mathrm{kg})$ and the other group low dose $1 / 20^{\text {th }}$ of $L D_{50}(4.75 \mathrm{mg} / \mathrm{kg})$ of fipronil dissolved in corn oil per animal per day orally for 90 days. One group was given corn oil placebo which served as the control group. Immediately after completion of the treatment period, seven animals from each group were anaesthetised xylazine-ketamine combination. After anaesthesia, E. coli LPS was administered @ 80 ug/animal via an intranasal route as described earlier (Pandit et al., 2016). The remaining seven animals from each group were given $80 \mu \mathrm{l}$ of standard saline solution (NSS) per mouse via the intranasal route. The animals were euthanised after nine hours of LPS/NSS exposure with a full dose of the xylazine-ketamine combination.

Microarray analysis: Animals were euthanised at the end of the experiment using xylazine ketamine euthanasia to collect the lungs. About $50 \mathrm{mg}$ of lung tissue was used from all the animals to isolate RNA using the Trizol method (Ambion, Life Technologies, USA) following the manufacturer's instructions. Microarray analysis was performed by One-color microarray-based exon analysis was performed using two mouse microarray slides (8x60K: Agilent-028005). Gene lists obtained after feature extraction were uploaded to Ingenuity Pathway Analysis (IPA), a web-based bioinformatics tool to obtain enriched pathways.

Quantitative real-time PCR: The lung tissue about $50 \mathrm{mg}$ was homogenised using magnetic beads, and total RNA was extracted from all the 
Pandit, A. A. and Sethi, R.S. / J. Appl. \& Nat. Sci. 11(2): 285- 290 (2019)

samples using trizol (Ambion, Life Technologies, USA) method following the manufacturer's instructions. The quality, as well as the quantity of the RNA, was assessed spectrophotometrically by Nanodrop (Thermo Fisher). The amount of total RNA used for cDNA synthesis was adjusted to $100 \mathrm{ng} / \mu \mathrm{L}$ for each sample. Total RNA was reverse transcribed into cDNA using a Revert aid cDNA synthesis kit (Thermo Scientific) according to the manufacturer's instruction. Quantitative real -time PCR was performed using SYBR green chemistry. The primers sequences used for genes were Pla2g5 by Bickford et al. (2013) and Actb by Yamaguchi et al. (2007). The reaction was carried in duplicates with Actb as the internal reference gene.

Immunohistochemistry: Immunohistochemical protein analysis was carried out the immunohistochemistry as described earlier by (Sethi et al., 2011, Sethi et al., 2013). The slides were incubated in a dark chamber with $1 \%$ BSA. The sections were stained with primary antibodies against mouse Pla2g5 (rabbit polyclonal Pla2g5; Abcam ab23709; dilution 1:200 followed by appropriate horseradish peroxidase (HRP)-conjugated secondary antibody (Polyclonal goat anti-rabbit; BA1000; dilution 1:400; Vector Laboratories). The reaction was visualised using a colour development kit (SK4600, Vector Laboratories, USA). The sections were counterstained with methyl green. Controls consisted of staining without primary antibody or secondary antibody or both.

\section{RESULTS AND DISCUSSION}

Recently we reported that fipronil and or endotoxin/LPS induces marked derangement in bronchoalveolar lavage fluid cytology along with histopathologic changes in lung tissue in a mice model. Further, transcriptomic analysis by Ingenuity pathway analysis revealed PCP pathway, Hmgb1 signalling, Eicosanoid signalling as the top enriched pathways elaborated in the lungs in mice in re-

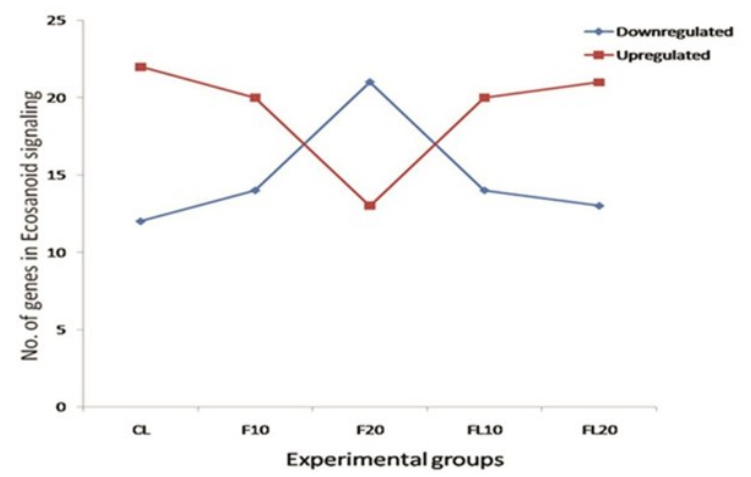

Fig. 1. No of genes dysregulated in eicosanoid signalling pathway between LPS (CL) fipronil at high dose (F10), fipronil at a low dose (F20), fipronil at high dose followed by LPS (FL10) and fipronil at low dose followed by LPS (FL20).

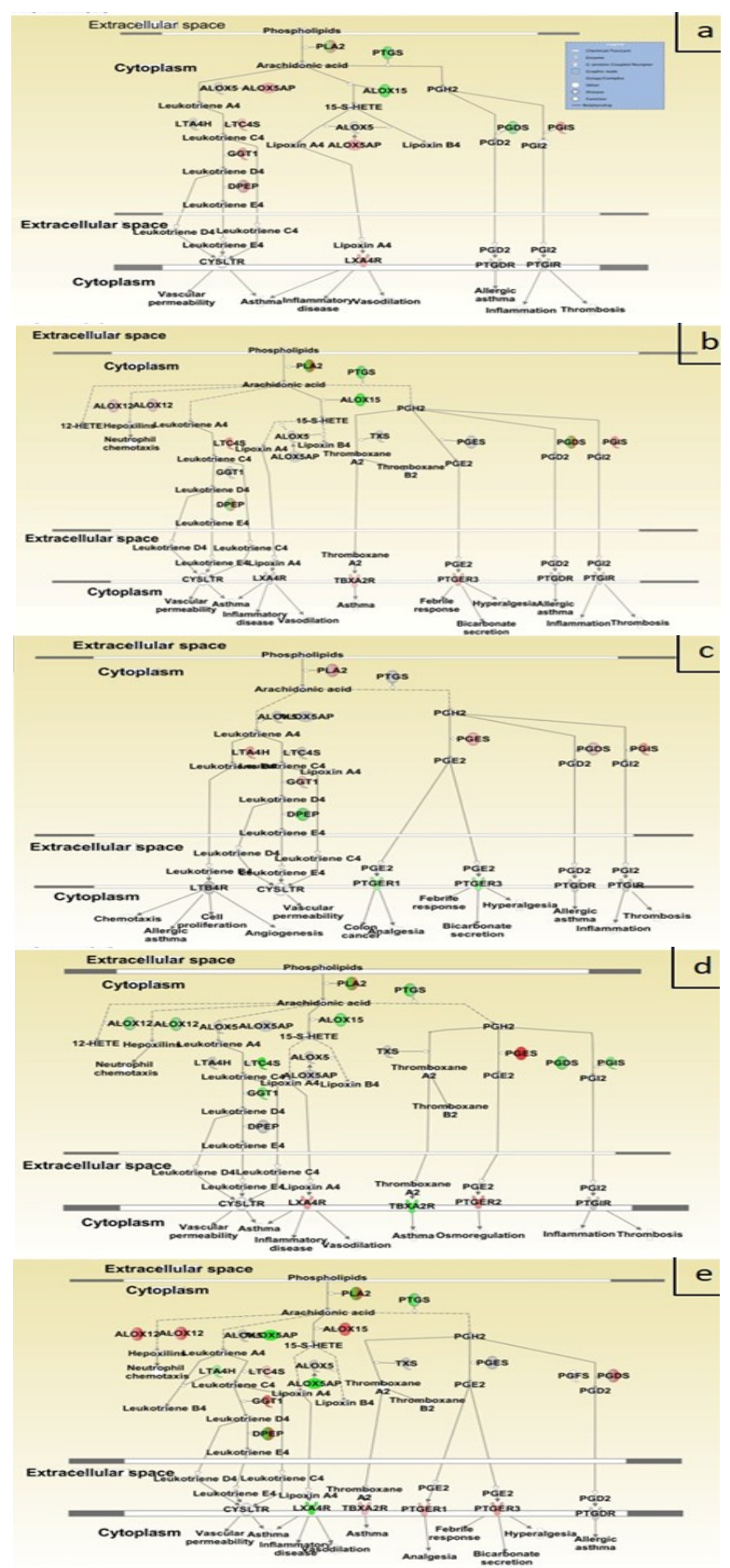

Fig. 2. Eicosanoid signalling pathway generated by Ingenuity pathway software in a) LPS (CL), b) fipronil at high dose (F10), c) fipronil at high dose followed by LPS (FL10), d) fipronil at low dose (F20), and e) fipronil at low dose followed by LPS (FL20).

sponse to fipronil and or LPS induced inflammation (Pandit et al., 2019).

Upon further analysing the micoarray data in present study, the number of genes dysregulated in Eicosanoid signalling pathway were 34 following exposure to LPS (21 upregulated and 12 downregulated), high dose of fipronil alone (19 upregulated and 15 downregulated) or in combination with LPS (20 upregulated and 14 downregulated), low dose of fipronil alone (11 upregulated and 21 downregulated) or in combination with LPS (21 
Pandit, A. A. and Sethi, R.S. / J. Appl. \& Nat. Sci. 11(2): 285- 290 (2019)
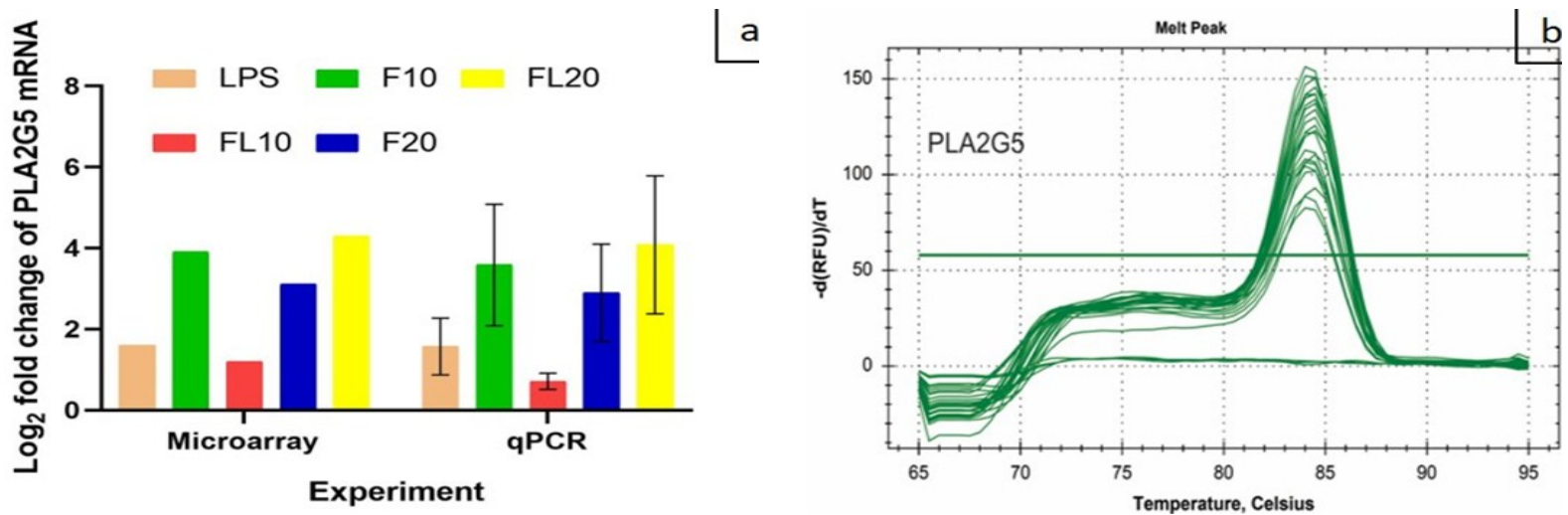

Fig 3. a) Fold change concordance of Pla2g5 by microarray and $q P C R$, b) Melt curve of Pla2g5 gene.

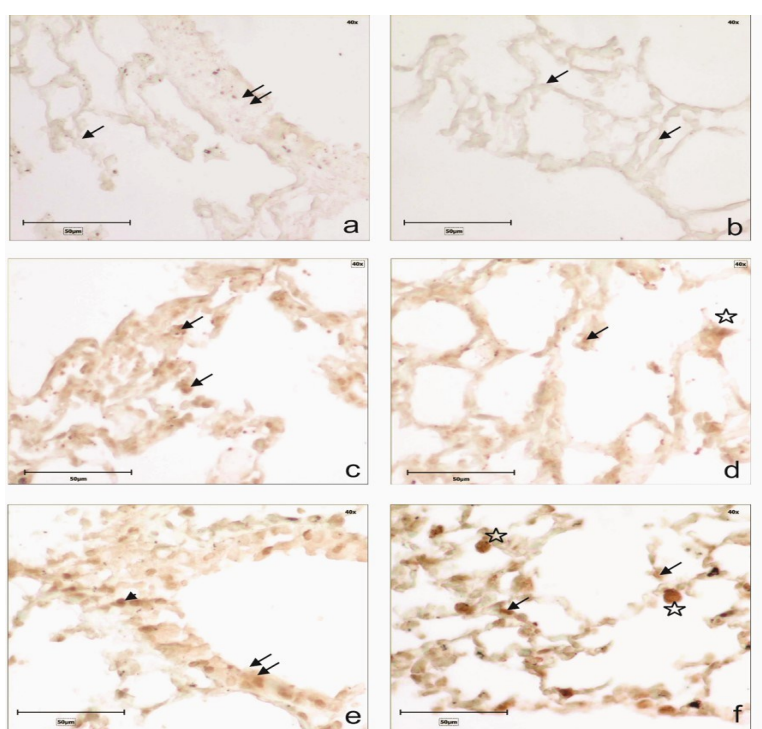

Fig. 4. Lung section stained with Pla2g5 primary antibody. Control sections without primary antibody $(a, b)$ resulted in no colour development in airways epithelium (double arrow) and alveolar septal cells (arrow). Biological Control group (c,d) showed a moderately immunopositive alveolar septal cells (arrow) alveolar macrophages (star) LPS (CL) resulted in moderately immunopositive reaction in $(e, f)$ airways epithelium (double arrow) alveolar septal cells (arrow), alveolar macrophages (star) and infiltrating cells (arrowhead). Original magnification a-e: $40 X$.

upregulated and 13 downregulated) (Fig 1). Ingenuity pathway software generated Eicosanoid signalling pathways in different experimental groups are presented in (Fig 2a-e). Eicosanoids are twenty carbon fatty acid derivatives including prostaglandins, leukotrienes and lipoxins and were discovered in 1930 (Burr and Burr, 1930). These Eicosanoids are produced inside a cell through an oxidative pathway from arachidonic acid and play a vital role in cytokine production, cell proliferation, antibody formation and antigen presentation (Harizi et al., 2008). The role of eicosanoids in immunity and the pathogenesis of pathophysiological conditions is confirmed by the fact that their

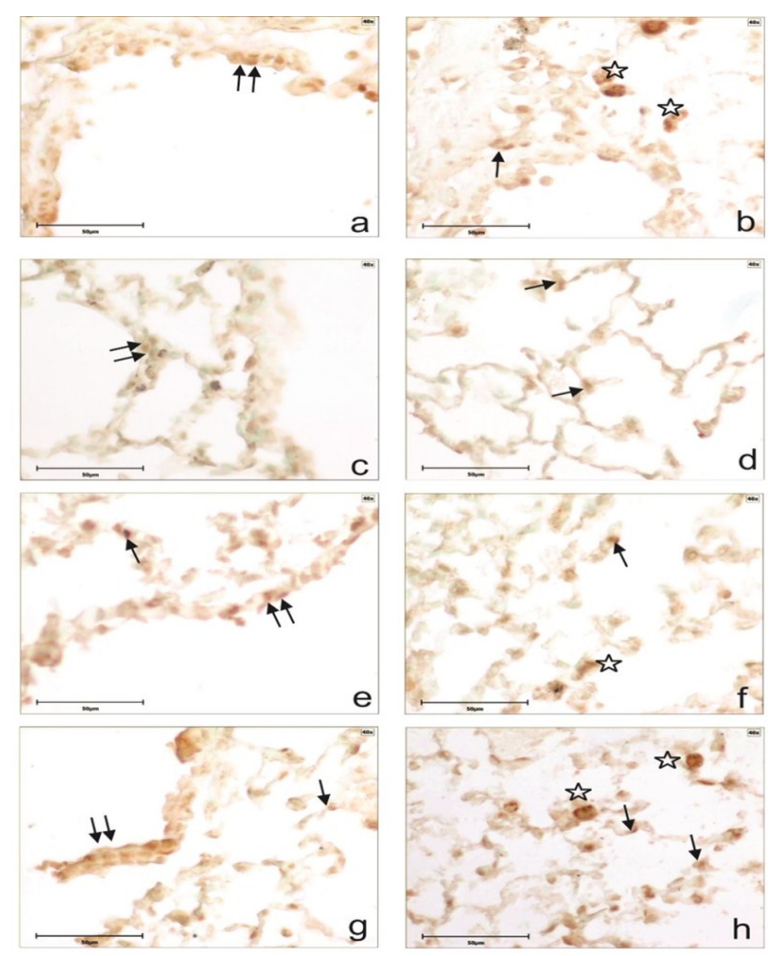

Fig. 5. Lung section stained with Pla2g5 primary antibody. Fipronil at high dose $(9.5 \mathrm{mg} / \mathrm{kg})$ (F10) $(a, b)$ resulted in strong colour development alveolar epithelium (double arrow), alveolar septal cells (arrow) and alveolar macrophages (star). The same dose combined with LPS (FL10) (c,d) showed a mildly immunopositive alveolar epithelium (double arrow) alveolar septal cells (arrow). Fipronil at a low dose $(4.75 \mathrm{mg} / \mathrm{kg}$ ) (F20) (e,f) showed moderately positive airways epithelium (double arrow) and alveolar septal cells (arrow), alveolar macrophages (star). Same dose when combined with LPS (FL20) $(g, h)$ resulted in again moderately immunopositive reaction in airways epithelium (double arrow) and alveolar septal cells (arrow) and alveolar macrophages (star). Original magnification $a-h$ : $40 X$.

production increases during inflammation (Ricciotti et al., 2011).

Group V phospholipase A2 (Pla2g5) is a lipidgenerating enzyme necessary for macrophage 
effector functions in pulmonary inflammation (Yamaguchi et al., 2018). Pla2g5 is one of the isoforms of phospholipase $A_{2}$ which generates eicosanoids from arachidonic acid and regulates eicosanoid signalling in various cell types (Kikawada et al., 2007). Transcriptome data analysis showed Pla2g5 as one of the differentially expressed genes in different experimental groups. Global view of DEG's (data not shown) revealed the up-regulation of Pla2g5 gene following exposure to fipronil with or without LPS. The increase was $1.6,3.9,1.2,3.1$ and 4.3 folds in LPS $(C L)$, fipronil at low high dose $(9.5 \mathrm{mg} / \mathrm{kg})$, fipronil at high dose followed by LPS, fipronil at a low dose (4.75 $\mathrm{mg} / \mathrm{kg}$ ) and fipronil at low dose followed by LPS respectively. We validated the expression of Pla2g5 mRNA using qPCR and immunohistochemistry and the qPCR data was found to be in concordance with the microarray data (Fig $3 a, b)$. The primary function of pro-inflammatory eicosanoids, leukotrienes and prostaglandins in the lungs is to operate as a chemoattractant which then recruits leukocytes to sites of lung inflammation. These recruited cells then enhance the innate immune cells to contain the inflammation and get rid of the foreign reagent (Kim et al., 1995). In the present investigation, the lung sections incubated without primary antibodies were used as a negative control during immunohistochemical staining and did not show any colour development (Fig 4 a,b). Immune positive alveolar epithelial cells and macrophages were also observed in the control group (Fig $4 \mathrm{c}, \mathrm{d}$ ). The essential cell types inside the body which secrete eicosanoids include tissue macrophages, dendritic cells and neutrophils with macrophages being the significant producers of eicosanoids (Back 2007). LPS resulted in a mild immunopositive reaction in alveolar airways cells (Fig 4 e,f) along with a significant amount of infiltrating cells around the alveolar airways and macrophages and small alveolar septal cells. High dose of fipronil (Fig 5 a,b) showed a strong positive reaction of airways epithelia and macrophages. The same dose in combination with LPS (Fig $5 \mathrm{c}$,d) resulted in a mild immunopositive response in the alveolar epithelial and small septa cells. Various inflammatory cells have been reported to produce eicosanoids along with mast cells lymphocytes and leukaemia cell lines (Burgermeister et al., 2000). In the present study, a low dose of fipronil with or without LPS showed immune-positive airways cells, macrophages and alveolar septal cells (Fig. 5 e,f). The principal function of pro-inflammatory eicosanoids, leukotrienes and prostaglandins in the lungs is to operate as a chemoattractant which then recruits leukocytes into the sites of lung inflammation as reported earlier (Ricciotti et al., 2011).

\section{Conclusion}

We concluded that pulmonary expression of Pla2g5 increases at mRNA and protein level following exposure to fipronil at both doses $(9.5 \mathrm{mg} /$ $\mathrm{kg}$ and $4.75 \mathrm{mg} / \mathrm{kg}$ ) with lower dose $(4.75 \mathrm{mg} / \mathrm{kg})$ showing more marked increase and data suggest a role Pla2g5 to activate eicosanoid signalling in fipronil and/or LPS induced lung inflammation in mice.

\section{REFERENCES}

1. Abhilash, P. C. and N. Singh. (2009). Pesticide use and application: An Indian scenario. Journal of Hazardous Materials, 165(1-3): 1-12. https:// doi.org/10.1016/j.jhazmat.2008.10.061.

2. Arif Ahmad Pandit, C. S. M., Ramneek And R.S. Sethi. (2018). Fipronil Induced Pulmonary Expression of Vcam-1 In Mice. Asian Journal of Microbiology, Biotechnology \& Environmental Sciences Paper 20 (Dec. Suppl. 2): 253-256.

3. Back, M. (2007). Leukotriene receptors: crucial components in vascular inflammation. ScientificWorldJournal. 7: 1422-1439. 10.1100/tsw.2007.187.

4. Bickford, J. S., C. Mueller, K. J. Newsom, S. J. Barilovits, D. E. Beachy, J. D. Herlihy, B. Keeler, T. R. Flotte and H. S. Nick. (2013). Effect of allergy and inflammation on eicosanoid gene expression in CFTR deficiency. J Cyst Fibros. 12(3): 258-265. 10.1016/ j.jcf.2012.08.014

5. Burgermeister, E., U. Pessara, U. Tibes, A. Küster, P. C. Heinrich and W. V. Scheuer. (2000). Inhibition of cytosolic phospholipase A2 attenuates activation of mitogen-activated protein kinases in human monocytic cells. European Journal of Pharmacology. 388(3): 195-208.

6. Burke, J. E. and E. A. Dennis. (2009). Phospholipase $\mathrm{A}(2)$ structure/function, mechanism, and signaling. Journal of Lipid Research. 50(Suppl): S237-S242. 10.1194/Jlr.R800033-JLR200.

7. Burr, G. O. and M. M. Burr. (1930). On the nature and role of the fatty acids essential in nutrition. Journal of Biological Chemistry. 86(2): 587-621.

8. Duquenne, P., G. Marchand and C. Duchaine. (2013). Measurement of endotoxins in bioaerosols at workplace: a critical review of literature and a standardization issue. Ann Occup Hyg. 57(2): 137-172. 10.1093/annhyg/mes051.

9. Giannattasio, G., D. Fujioka, W. Xing, H. R. Katz, J. A. Boyce and B. Balestrieri. (2010). Group V secretory phospholipase $A 2$ reveals its role in house dust mite-induced allergic pulmonary inflammation by regulation of dendritic cell function. $J$ Immunol. 185 (7): 4430-4438. 10.4049/jimmunol.1001384.

10.Gupta, P. K. (2004). Pesticide exposure--Indian scene. Toxicology. 198(1-3): 83-90. 10.1016/ j.tox.2004.01.021.

11. Hainzl, D. and J. E. Casida. (1996). Fipronil insecticide: novel photochemical desulfinylation with retention of neurotoxicity. Proc Natl Acad Sci U S A. 93 (23): 12764-12767.

12. Harizi, H., J. B. Corcuff and N. Gualde. (2008). Arachidonic-acid-derived eicosanoids: roles in biology and immunopathology. Trends Mol Med. 14(10): 461 469. 10.1016/j.molmed.2008.08.005.

13.Hossard, L., A. Philibert, M. Bertrand, C. Colnenne- 
David, P. Debaeke, N. Munier-Jolain, M. H. Jeuffroy, G. Richard and D. Makowski. (2014). Effects of halving pesticide use on wheat production. Scientific Reports. 4: 4405. 10.1038/srep04405https:// www.nature.com/articles/srep04405\#supplementaryinformation.

14.Kannan, K., S. Tanabe and R. Tatsukawa. (1995). Geographical distribution and accumulation features of organochlorine residues in fish in tropical Asia and Oceania. Environ Sci Technol. 29(10): 2673-2683. 10.1021/es00010a032.

15.Kidd, H. and D. R. James (1991). The agrochemicals handbook.

16.Kikawada, E., J. V. Bonventre and J. P. Arm. (2007). Group V secretory PLA(2) regulates TLR2dependent eicosanoid generation in mouse mast cells through amplification of ERK and $\operatorname{CPLA}(2) \alpha$ activation. Blood. 110(2): 561-567. 10.1182/blood2006-10-052258.

17.Kim, D. K., T. Fukuda, B. T. Thompson, B. Cockrill, C. Hales and J. V. Bonventre. (1995). Bronchoalveolar lavage fluid phospholipase A2 activities are increased in human adult respiratory distress syndrome. Am J Physiol. 269(1 Pt 1): L109-118.

18.Liu, D., P. Wang, W. Zhu, X. Gu, W. Zhou and Z. Zhou. (2008). Enantioselective degradation of fipronil in Chinese cabbage (Brassica pekinensis). Food Chem. 110(2): 399-405. 10.1016/ j.foodchem.2008.02.017.

19.Merkowsky, K., R. S. Sethi, J. P. S. Gill and B. Singh. (2016). Fipronil induces lung inflammation in vivo and cell death in vitro. Journal of Occupational Medicine and Toxicology (London, England). 11: 10. 10.1186/s12995-016-0102-0.

20.Ohta, S., M. Imamura, W. Xing, J. A. Boyce and B. Balestrieri. (2013). Group V secretory phospholipase A2 is involved in macrophage activation and is sufficient for macrophage effector functions in allergic pulmonary inflammation. J Immunol. 190(12): 59275938. 10.4049/jimmunol.1203202.

21.Pandit, A. A., S. Choudhary, Ramneek, B. Singh and R. S. Sethi. (2016). Imidacloprid induced histomorphological changes and expression of TLR-4 and TNFalpha in lung. Pestic Biochem Physiol. 131: 9-17. 10.1016/j.pestbp.2016.02.004.

22.Pandit, A. A., R. K. Gandham, C. S. Mukhopadhyay, R. Verma and R. S. Sethi. (2019). Transcriptome analysis reveals the role of the PCP pathway in fipronil and endotoxin-induced lung damage. Respiratory Research. 20(1): 24. 10.1186/s12931-019-0986 -1 .

23.Pandit, A. A., C. S. Mukhopadhyay and R. S. Sethi. (2017). Expression of TLR-9 and IL-1 following Concomitant Exposure to Imidacloprid and Endotoxin. Pesticide Research Journal. 29(2): 243-250.

24.Ricciotti, E. and G. A. FitzGerald. (2011). Prostaglandins and inflammation. Arteriosclerosis, thrombosis, and vascular biology. 31(5): 986-1000. 10.1161/ ATVBAHA.110.207449.
25.Sandeep, K., C. S. Mukhopadhyay, J. S. Arora and R. S. Sethi. (2016). Indoxacarb interaction alters immunotoxic and genotoxic potential of endotoxin. Journal of pesticide science. 41(3): 65-70. 10.1584/ jpestics.D16-012.

26.Sethi, R. S., R. S. Brar, O. Singh and B. Singh. (2011). Immunolocalization of Pulmonary Intravascular Macrophages, TLR4, TLR9 and IL-8 in Normal and Pasteurella multocida-infected Lungs of Water Buffalo (Bubalus bubalis). Journal of Comparative Pathology. 144(2): 135-144. https://doi.org/10.1016/ j.jcpa.2010.08.003.

27.Sethi, R. S., D. Schneberger, C. Charavaryamath and B. Singh. (2017). Pulmonary innate inflammatory responses to agricultural occupational contaminants. Cell Tissue Res. 367.

28.Sethi, R. S., D. Schneberger and B. Singh. (2013). Characterization of the lung epithelium of wild-type and TLR9-/- mice after single and repeated exposures to chicken barn air. Experimental and Toxicologic Pathology. 65(4): 357-364. https:/l doi.org/10.1016/j.etp.2011.11.002.

29.Subhash, P.S., Chand, P., Pavithra, S., Balaji, S. J., \& Pal, S. (2017). Pesticide Use in Indian Agriculture: Trends, Market Structure and Policy Issues.

30.Tewari, A., R. S. Sethi, H. S. Banga, B. Singh and J. Gill. (2017). Concomitant effect of low dose of lindane and intranasal lipopolysaccharide on respiratory system of mice. Hum Exp Toxicol. 36(11): 1201-1211. 10.1177/0960327116685889.

31.Tischfield, J. A., Y. R. Xia, D. M. Shih, I. Klisak, J. Chen, S. J. Engle, A. N. Siakotos, M. V. Winstead, J. J. Seilhamer, V. Allamand, G. Gyapay and A. J. Lusis. (1996). Low-molecular-weight, calciumdependent phospholipase A2 genes are linked and map to homologous chromosome regions in mouse and human. Genomics. 32(3): 328-333. 10.1006/ geno.1996.0126.

32.Tomlin, C. D. (2009). The pesticide manual: a world compendium, British Crop Production Council.

33.Verma Geetika, Verma Ramneek, Mukhopadhyay CS and Sethi RS. (2016). Acute ethion exposure alters expression of TLR 9 in lungs of mice. Indian Journal of Veterinary Anatomy 28 (1): 40-43.

34.Verma, G., C. S. Mukhopadhyay, R. Verma, B. Singh and R. S. Sethi. (2018). Long-term exposures to ethion and endotoxin cause lung inflammation and induce genotoxicity in mice. Cell Tissue Res. 10.1007/ s00441-018-2912-0.

35.Yamaguchi, M., S. K. Samuchiwal, O. Quehenberger, J. A. Boyce and B. Balestrieri. (2018). Macrophages regulate lung ILC2 activation via Pla2g5dependent mechanisms. Mucosal Immunol. 11(3): 615-626. 10.1038/mi.2017.99.

36. Yamaguchi, Y., K. Fujio, H. Shoda, A. Okamoto, N. H. Tsuno, K. Takahashi and K. Yamamoto. (2007). IL -17B and IL-17C are associated with TNF-alpha production and contribute to the exacerbation of inflammatory arthritis. J. Immunol. 179(10): 7128-7136. 